\title{
LA EXCAVACIÓN ARQUEOLÓGICA DE LOS GRANDES ALMACENES EL PILAR (SANTIAGO DE COMPOSTELA, GALICIA, ESPAÑA): UN ESTUDIO ARQUEOBOTÁNICO DE SILOS DE ALMACENAJE MEDIEVALES
}

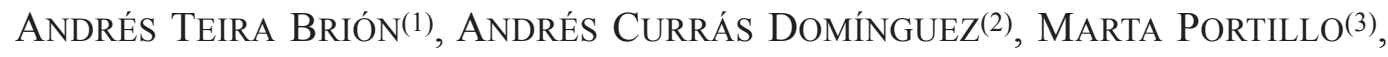 \\ Rosa M. AlberT(4) \& MANUEla PÉREZ MATO(5)
}

\section{Resumen}

Abstract
Los estudios arqueobotánicos no han tenido en el área gallega un gran desarrollo en yacimientos medievales exceptuando algunos análisis antracológicos. Tampoco ha sido habitual la aplicación de métodos de identificación de polen y fitolitos para estructuras tipo silos, no solo para esta época sino en la investigación arqueológica del NW peninsular en general. El hallazgo de varias fosas en el contexto de la intervención arqueológica de los Grandes Almacenes El Pilar (Santiago de Compostela, Galicia) constituye un interesante punto de partida para la aplicación de este tipo análisis contextualizado en un momento importante del desarrollo de la ciudad de Santiago, el proceso de crecimiento del burgo en la transición de la Alta a la Baja Edad Media. Este estudio aporta datos que ayudan a interpretar el uso concreto de las estructuras excavadas - como estructuras de almacenaje de trigo -, que difícilmente se podría haber establecido tan sólo a partir de la tipología de dichas estructuras.

Palabras clave: Edad Media; noroeste ibérico; Galicia; arqueobotánica; silos; polen; fitolitos.

\begin{abstract}
The archaeological excavation of Grandes Almacenes El Pilar (Santiago de Compostela, Spain): an archaeobotanical study of medieval storage pits.

The use of archaeobotanical studies in medieval archaeological sites from Galicia, is not usual, except for occasional charcoal analyses. Pollen and phytolith identification in relation to storage pits is also rare, not only for this period but also for archaeological research in NW Iberia in general. The identification of several pits in the archaeological site of Grandes Almacenes El Pilar (Santiago de Compostela, Galicia) offered the opportunity to apply these types of analyses and in this way shed more light on the use of these structures at the end of the Early Medieval period in Santiago, a time when the city was developing and expanding. This study provides new information on the use of these features as storage pits for wheat, and shows the potential of pollen and phytolith analyses in complementing typological studies and aiding in interpretation.
\end{abstract}

Keywords: Middle Age; NW Iberia; Galicia; archaeobotany; storage pits; pollen; phytoliths.

\section{INTRODUCCIÓN}

Durante los años 2009 y 2010, en el número 23 de la Rúa do Preguntoiro de Santiago de Compostela se desarrolló una intervención arqueológica en el interior del solar que previamente habían ocupado los Grandes Almacenes El Pilar ${ }^{1}$ (Fig. 1). La cons- trucción de este comercio en el siglo XX provocaría importantes modificaciones que alteraron el edificio que en origen fue el Pazo de los Condes de Ximonde. Las obras afectaron también a otra construcción contigua, con entrada desde la Praza da Pescadería Vella, objeto de una profunda excavación que destruyó la secuencia estratigráfica existente. Sin

(1) Grupo de Estudos para a Prehistoria do NW Ibérico - GEPN. Departamento de Historia I. Universidade de Santiago de Compostela. andresteirabrion@gmail.com

(2) Seminari d'Estudis i Recerques Prehistòriques - SERP. Departament de Prehistòria, Història Antiga i Arqueologia. Universitat de Barcelona. andrescurras@gmail.com

(3) Subprograma Juan de la Cierva, Ministerio de Ciencia e Innovación - MICINN /GEPEG. Departament de Prehistòria, Història Antiga i Arqueologia. Universitat de Barcelona. mpartillo@ub.edu

(4) ICREA Research Profesor / GEPEG, Departament de Prehistòria, Història Antiga i Arqueologia. Universitat de Barcelona. rmalbert@ ub.edu

(5) Grupo de Estudos Integrais do Territorio - GESIT. gesit2@orange.es

1 La excavación, en las obras de edificación de un auditorio promovido por Novacaixagalicia, fue dirigida por Manuela Pérez. 


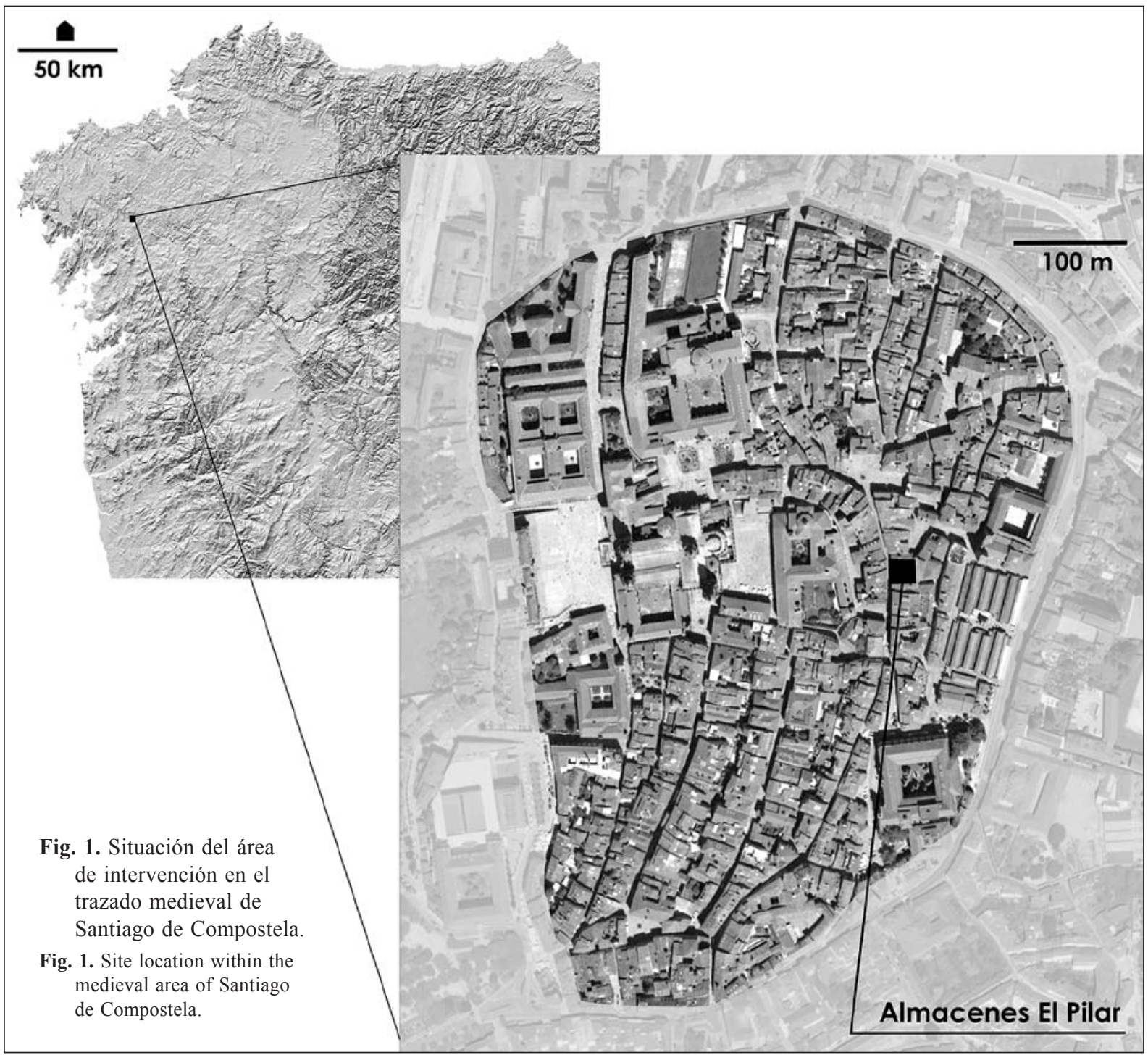

embargo, bajo el pavimento de lo que había sido la casa palaciega se conservaron diversos vestigios de estructuras anteriores a esta reforma. De todos ellos, cobró un especial interés la existencia de una ocupación medieval formada por fosas excavadas en el sustrato, la mayoría de planta circular y de diversas profundidades.

En el presente trabajo, se exponen los resultados de los análisis arqueobotánicos - polen y fitolitos realizados con la finalidad de conocer la función y el uso de estas estructuras, abandonadas en el contexto de los siglos XI-XII. Momento en el que Compostela experimenta un importante desarrollo y un cambio en su configuración urbana, pasando del locus Sancti Iacobi de aproximadamente 3 Ha de extensión y barrios anexos en el siglo X (LÓPEZ ALSINA 1988), a las $30 \mathrm{Ha}$ de la villa amurallada que conocemos en la actualidad como la Cidade Vella.

\section{Contexto ARQueológico}

En el estado actual de la investigación desconocemos la fecha exacta de construcción del pazo de Ximonde, que podríamos situar aproximadamente en época bajomedieval/moderna. Tal y como se desprende del estudio de fuentes documentales, en origen existiría un edificio principal en el sector oeste - hacia la calle del Preguntoiro - y un espacio de huerta en el sector este, separados ambos por un callejón cubierto documentado en el plano histórico de Compostela de 1783 (vid. Rosende 1999). Entre 1893 y 1910 el espacio vacío se ocupó en su totalidad por un nuevo edificio.

Durante la excavación arqueológica se exhumaron restos correspondientes al pazo original, orientado a la calle del Preguntoiro (Fig. 2). Al igual que en otras muchas construcciones de Santiago, este edificio es- 


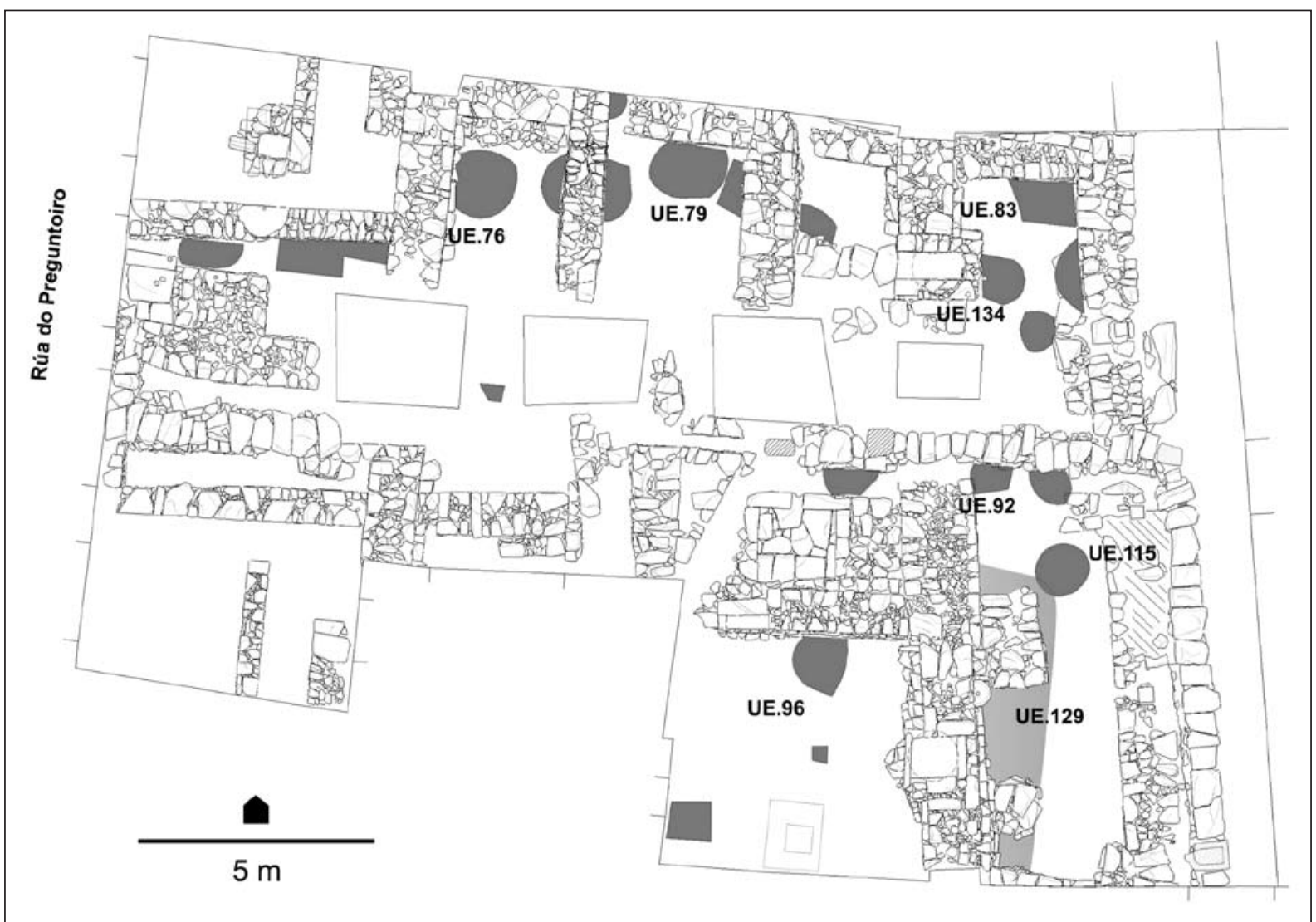

Fig. 2. Planta de la intervención: fosas y cortes medievales (sombreado) y estructuras del Pazo de Ximonde. Sólo se enumeran las UEs referidas en el texto (Planimetría de María Méndez Martínez).

Fig. 2. Plan of the inervention showing the pits and medieval features (shaded and the structures of the Pazo de Ximonde. Only the contexts referred to in the text are numbered (Plan by María Méndez Martínez).

taría precedido por un vestíbulo o soportales al este que posiblemente también existirían al oeste - aunque no se han encontrado restos -. En el interior, las estructuras murarias se corresponden con divisiones y estancias del pazo, pozos para el abastecimiento de agua - uno de $2 \mathrm{~m}$ y otro de más de $5 \mathrm{~m}$ de profundidad -, el semisótano y una red de pluviales constituida por dos canales pétreos con salidas al oeste y al este enlazados con la red pública.
Bajo las estructuras murarias, casi en su totalidad correspondientes al Pazo de Ximonde, se hallaron 17 fosas de planta circular y tres de planta cuadrangular, de las que fueron excavadas 14 (Figs. 2 e 3). La intervención permitió documentar diversas profundidades de las estructuras, debido posiblemente a una diferenciación funcional. Varios cortes tienen entre 0,30 y $0,50 \mathrm{~m}$ de profundidad, entre los que se encuentran los de planta cuadrangular, mientras

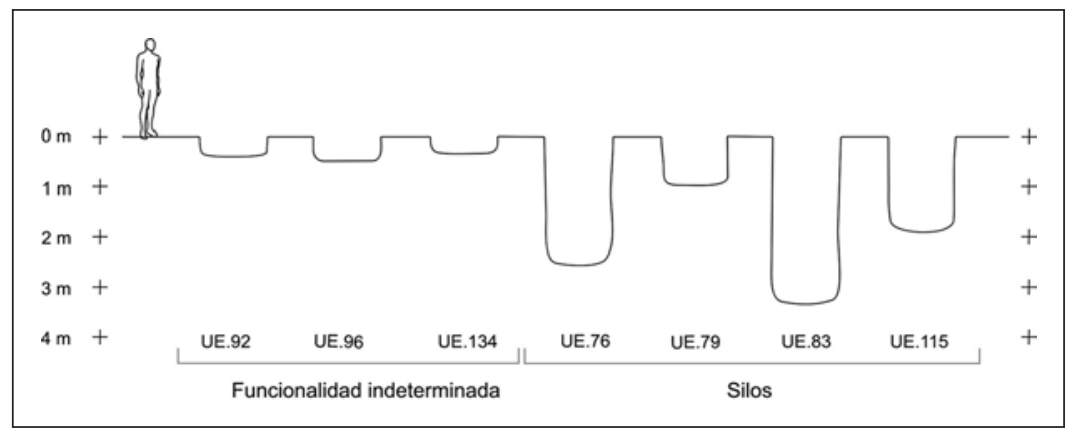

Fig. 3. Diferentes profundidades de las fosas medievales.

Fig. 3. Differences in depths of the medieval pits. 
otros, morfológicamente asociables a estructuras tipo silo, desarrollan de 1 a 3,3 m de profundidad.

No contamos con evidencias arqueológicas ni documentales que nos indiquen el comienzo de la explotación de las fosas. Para la determinación de la fecha de abandono se analizaron varias muestras de sedimento por termoluminiscencia (TM), luminiscencia ópticamente estimulada (OSL) (Fig. 4) y carbono 14 mediante AMS en carbones recogidos en el depósito de relleno (Fig. 5). Las dataciones por TM y OSL se realizaron en el Instituto Universitario de Xeoloxía Isidro Parga Pondal de la Universidade de A Coruña. Las dataciones de AMS, enviadas por este instituto, fueron procesadas por Beta Analytic (vid. SANJURJo 2010). Los resultados de los análisis apuntan a que su abandono se inició a partir del siglo XI, al que también pertenece parte de la cerámica recogida, aún en fase de estudio.

En función de los resultados de las dos muestras del depósito de relleno la UE76 se debe ajustar el sellado de la estructura en el intervalo comprendido entre 1045-1244 AD, pues como es lógico la muestra P-76-2 no puede ser más antigua que la P-76-1 al pertenecer a un depósito superior estratigráficamente, ni tampoco P-76-1 tener una fecha final más reciente que P-76-2 por el mismo motivo.

También debemos matizar las dataciones de C14, pues presentan intervalos más antiguos que las fechas de TM y OSL para las mismas muestras. Al no existir carbones asociados al funcionamiento de las fosas, sólo como inclusiones en los depósitos de relleno, estos se encontrarían desplazados de su contexto original y existiría un desfase entre el inicio de la pérdida de carbono y su transporte a la estructura, datando una combustión independiente - anterior o coetánea - al episodio de colmatación.

\section{Contexto Paleoambiental}

El período que comprende los siglos IX a XII en el noroeste de la Península Ibérica ha sido definido como una época de bonanza climática. Diversos trabajos realizados sobre sedimentos de Galicia han permitido caracterizar con fiabilidad cronológica las condiciones climáticas existentes en el final de la Alta Edad Media y su transición hacia los siglos plenamente medievales, estableciendo para este período un incremento general de la humedad y de la temperatura (MARTÍNEZ-CORTIZAS et al. 1999; RAMIL-REGO et al. 2009). Esta situación supone un cambio en relación con el período climático anterior, definido entre el final de la administración romana en Galicia y el desarrollo de las campañas musulmanas del siglo VIII, y que se caracterizó por la existencia de condiciones térmicas más frescas y de menor humedad (DESPRAT et al. 2003). El aumento de temperaturas en el noroeste Ibérico tuvo lugar en el siglo IX y perduró hasta época bajomedieval, a partir de la cual diferentes indicadores paleoclimáticos anuncian el paulatino enfriamiento que caracterizó la Pequeña Edad del Hielo. En este sentido, el noroeste Ibérico sigue la evolución climática general registrada en el hemisferio norte para estas cronologías (BRADLEY et al. 2003), pudiendo reconocerse en Galicia (LEBREIRO et al. 2006) los efectos del Medieval Warm Period.

Pese a reconocerse diferentes ritmos en la evolución vegetal de diversos territorios de Galicia, en general durante los siglos centrales de la Edad Media se producen significativos episodios de deforestación (Muñoz-Sobrino et al. 1997; Desprat et al. 2003; Martínez-Cortizas et al. 2005), los cuales coinciden con un aumento de los indicadores de cultivos y otras plantas adventicias, revelando procesos de

\begin{tabular}{|l|l|c|c|c|c|}
\hline Estructura & Muestra & $\begin{array}{c}\text { Profundidad } \\
\text { estructura }\end{array}$ & $\begin{array}{c}\text { Profundidad } \\
\text { muestra }\end{array}$ & $\begin{array}{c}\text { Edad } \\
\text { convencional AD }\end{array}$ & Intervalo \\
\hline UE76 & P-76-1 & $2,50 \mathrm{~m}$ & $2,45 \mathrm{~m}$ & $1173 \pm 128$ & $1045-1301 \mathrm{AD}$ \\
\hline UE76 & P-76-2 & $2,50 \mathrm{~m}$ & $2,00 \mathrm{~m}$ & $1134 \pm 110$ & $1024-1244 \mathrm{AD}$ \\
\hline UE115 & P-115-C & $1,90 \mathrm{~m}$ & $1,70 \mathrm{~m}$ & $1092 \pm 132$ & $960-1225 \mathrm{AD}$ \\
\hline UE129 & PL-1 & $0,60 \mathrm{~m}$ & $0,45 \mathrm{~m}$ & $946 \pm 112$ & $834-1058 \mathrm{AD}$ \\
\hline
\end{tabular}

Fig. 4. Dataciones por termoluminiscencia y luminiscencia ópticamente estimulada (a partir de J. Sanjurjo 2010).

Fig. 4. Thermoluminescenc and optically stimulated luminescence dates (from J. Sanjuro 2010).

\begin{tabular}{|l|c|c|c|c|}
\hline $\begin{array}{l}\text { Código de } \\
\text { laboratorio }\end{array}$ & Estructura & Muestra & $\begin{array}{c}\text { Edad } \\
\text { convencional AD }\end{array}$ & $\begin{array}{c}\text { Edad calibrada } \\
\text { a 2 sigma }\end{array}$ \\
\hline Beta-273038 & UE76 & P-76-2 & $980 \pm 40$ & $990-1160 \mathrm{cal}$ AD \\
\hline Beta-273039 & UE115 & P-115-C & $1070 \pm 40$ & $890-1030 \mathrm{cal} \mathrm{AD}$ \\
\hline
\end{tabular}

Fig. 5. Dataciones de C14 por la técnica de AMS (a partir de J. Sanjurjo 2010).

Fig. 5. AMS C14 dates (from J. Sanjurjo 2010). 
antropización. No obstante, los cambios paisajísticos relacionados con la intervención antrópica en el territorio gallego comenzaron con anterioridad a la época medieval, teniendo lugar sobre todo en los sectores menos elevados de la geografía, como los de la Galicia occidental. Entorno a los siglos X y XI, y en ocasiones desde el siglo VII (Martínez-Cortizas et al. 2005), diversos registros altimontanos revelan el aumento de la presión antrópica sobre el territorio, que alcanzó cotas altitudinales más elevadas en el marco expansivo de la economía medieval.

\section{Materiales y Métodos}

\subsection{Muestras}

El objetivo principal del estudio arqueobotánico fue determinar el uso de las fosas encontradas durante la excavación arqueológica. Con el objetivo de realizar una caracterización funcional de estas estructuras se realizaron varios tipos de análisis, se documentaron los restos arqueológicos que pudieran determinar las actividades realizadas en su interior, así como la presencia de algún tipo de tratamiento o revestimiento en las paredes de los cortes.

Teniendo en cuenta estas premisas se recogieron cuatro muestras pertenecientes a dos estructuras negativas, UE76 y UE129, mediante el raspado de la superficie de la fosa. Se extrajo un volumen de $120 \mathrm{ml}$ de sedimento por muestra en la zona de la pared y en el fondo de las estructuras, por ser el área que potencialmente pudiese conservar restos relacionados con su uso. No se recogieron, excepto en un caso y como muestra control (MO-03), en los niveles de relleno, pues podrían corresponder a su amortización posterior como basureros o con su mismo tapado, y por lo tanto con la pérdida de su funcionalidad original.

Las muestras arqueobotánicas proceden de:

- UE76. Estructura negativa de sección cilíndrica de 1,3 m de diámetro en planta, y 2,5 m de profundidad excavada en el substrato. Su fondo es plano. Se recogieron tres muestras: MO-01, MO-02 y MO-03. La muestra 01 procede del raspado de la pared del corte en su ruptura con el fondo. La MO-02 del fondo, y la MO-03 de la parte superior del primer depósito de relleno de la fosa. La MO-03 serviría para observar posibles diferencias en la composición de los restos respecto a los conservados en la pared (Fig. 6).

- UE129. Interfacies de morfología tendente a cuadrangular situada bajo varias estructuras pétreas que impiden observar su configuración en planta (vid. Fig. 2). La muestra (MO-04) se recogió del sedimento en contacto con el substrato.

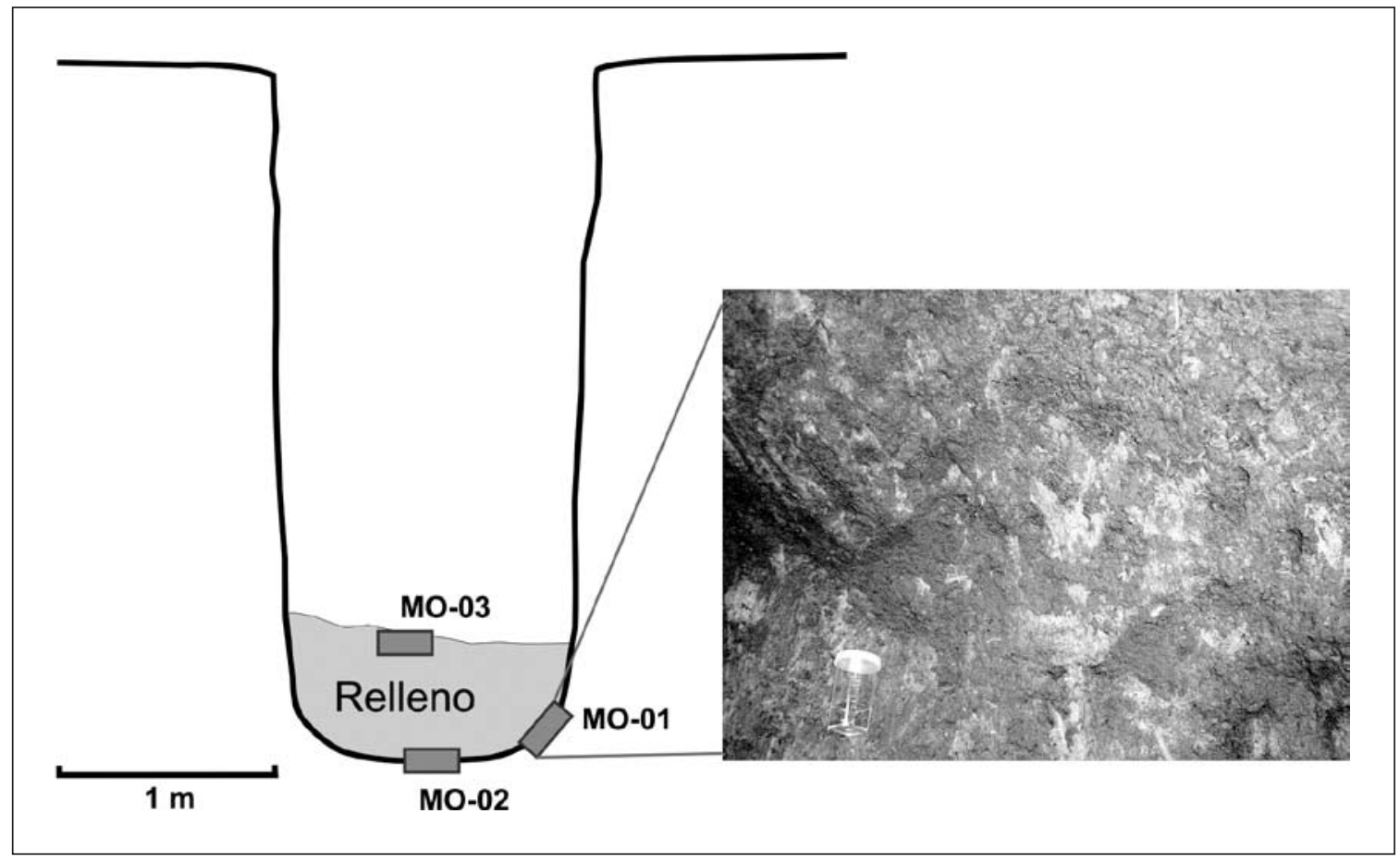

Fig. 6. Croquis de sección de la UE76 con las zonas de recogida de las muestras y detalle de la pared del corte. Fig. 6. Section drawing of UE76 showing the areas where samples were taken and showing the profile of the cut. 
En función de los objetivos, se consideró oportuno el estudio de polen y fitolitos de todas las muestras. El análisis de polen ha sido realizado por Andrés Currás, y el de fitolitos por Marta Portillo y Rosa M. ${ }^{\mathrm{a}}$ Albert. También se solicitaron analíticas al Instituto de Cerámica de la USC para verificar la existencia de algún tipo de material orgánico o mineral diferente al del substrato: un análisis mineralógico de la muestra MO-02 de la UE76 mediante técnicas combinadas de Difracción de Rayos X (DRX) y Análisis Termodiferencial y Termogravimétrico (ATD-TG), y análisis químico mediante espectrometría de emisión atópica con plasma inductivo (ICP) sobre las paredes de la UE76 (MO-01, MO-02) y de la UE129 (MO-04) (Fig. 7).

\begin{tabular}{|l|c|c|c|c|c|}
\hline Estructura & Muestra & Polen & Fitolitos & Químico & Mineralógico \\
\hline UE76 & MO-01 & $\bullet$ & $\bullet$ & $\bullet$ & \\
\hline UE76 & MO-02 & $\bullet$ & $\bullet$ & $\bullet$ & $\cdot$ \\
\hline UE76 & MO-03 & $\bullet$ & $\bullet$ & & \\
\hline UE129 & MO-04 & $\bullet$ & $\bullet$ & $\bullet$ & \\
\hline
\end{tabular}

Fig. 7. Tipo de análisis realizados por estructura y muestra.

Fig. 7. Example of the analysis undertaken for structure and sample.

\subsection{Métodos}

\subsubsection{Polen}

El tratamiento físico y químico de las muestras tuvo lugar en el laboratorio de arqueología de la Universidad de Barcelona, se empleó aproximadamente $2 \mathrm{~g}$ de material por cada muestra y se siguió el protocolo estándar de K. Fægri e J. Iversen (1989), el cual emplea ácidos y bases para concentrar el material polínico. La solución resultante fue montada en portaobjetos con solución de glicerina y analizada con un microscopio Zeiss Axiostar y objetivos en seco de 40X y 63X. La identificación del polen fósil se llevó a cabo a partir de las publicaciones de M. Reille (1992) y H.-J. Beug (2004). Un mínimo de 250 granos de polen fueron contados por muestra para conseguir una suma base estadísticamente representativa (Mc ANDREWS \& KING 1976; JANSSEN 1981), en función de la cual fueron calculados los porcentajes de cada taxón o tipo polínico presente en la muestra. Esta suma también sirvió para calcular los porcentajes de representación de microfósiles no polínicos (NPP) (VAN GEEL \& APTROOT 2006). Los valores porcentuales de cada taxón fueron representados en un diagrama de barras donde figuran las cuatro muestras, así como en un gráfico elaborado por cada una de las muestras, que clarifica la distribución relativa de los taxones más significativos.

\subsubsection{Fitolitos}

La metodología empleada en la extracción de los fitolitos sigue la propuesta por R.M. Albert et al. (1999). Una muestra de sedimento de $1 \mathrm{~g}$ aproximadamente es tratada con $10 \mathrm{ml}$ de una solución de ácido clorhídrico $(3 \mathrm{~N} \mathrm{HCl})$ y ácido nítrico $(3 \mathrm{~N}$ $\mathrm{HNO}_{3}$ ). Posteriormente se añaden $10 \mathrm{ml}$ de Peróxido de Hidrógeno $\left(\mathrm{H}_{2} \mathrm{O}_{2}\right)$ al $30 \%$. Mediante estos procesos se eliminan carbonatos y fosfatos, así como la materia orgánica, para dejar únicamente los componentes resistentes a los ácidos dentro de los cuales se incluyen los fitolitos. La fracción resultante del ataque del ácido se denomina "fracción insoluble al ácido" (FIA). Sus componentes minerales son separados por densidades usando $5 \mathrm{ml}$ de Polytungstato de Sodio $\left[\mathrm{Na}_{6}\left(\mathrm{H}_{2} \mathrm{~W}_{12} \mathrm{O}_{40}\right) \cdot \mathrm{H}_{2} \mathrm{O}\right]$ a $2.4 \mathrm{~g} / \mathrm{ml}$. Para examinar las muestras en el microscopio, se preparan láminas con $\sim 1 \mathrm{mg}$ de material utilizando Entellan New (Merck). El área total de la muestra en la lámina se estima contando el número total de campos que contienen sedimento. Los fitolitos son cuantificados en un número conocido de campos escogidos aleatoriamente a $400 \times$. Siempre que es posible se procura contabilizar un mínimo de 200 fitolitos; se ha demostrado que el contaje de 200 fitolitos presenta un margen de error de $\sim 20 \%$ (ALBERT \& WEINER 2001). La adscripción morfológica de los fitolitos se basa, entre otros, en P.C. Twiss et al. (1969), D.A. Brown (1984), S.C. Mulholland y Jr.G. Rapp (1992), D.R. Piperno (2006) y la terminología en R.M. Albert (2000) así como en el Código Internacional de Nomenclatura de Fitolitos (MADELLA et al. 2005). La caracterización taxonómica de las estructuras multicelulares se fundamenta en A.M. Rosen (1992). Las muestras han sido examinadas con un microscopio óptico Olympus BX-41 y las imágenes digitales capturadas con una cámara Color View Ilu de Olympus.

\section{Resultados}

A lo largo de este apartado nos centraremos en los datos aportados por los análisis arqueobotánicos de polen (Fig. 8) y fitolitos. Sin embargo, antes debemos exponer brevemente algunas de las conclusiones de los demás análisis, pues nos han servido para comprobar, en un principio, la ausencia de tratamiento o revestimiento de origen inorgánico en la fosa UE76. Los elementos encontrados en el análisis mineralógico se corresponden con componentes del substrato natural, compuesto por minerales constituyentes 


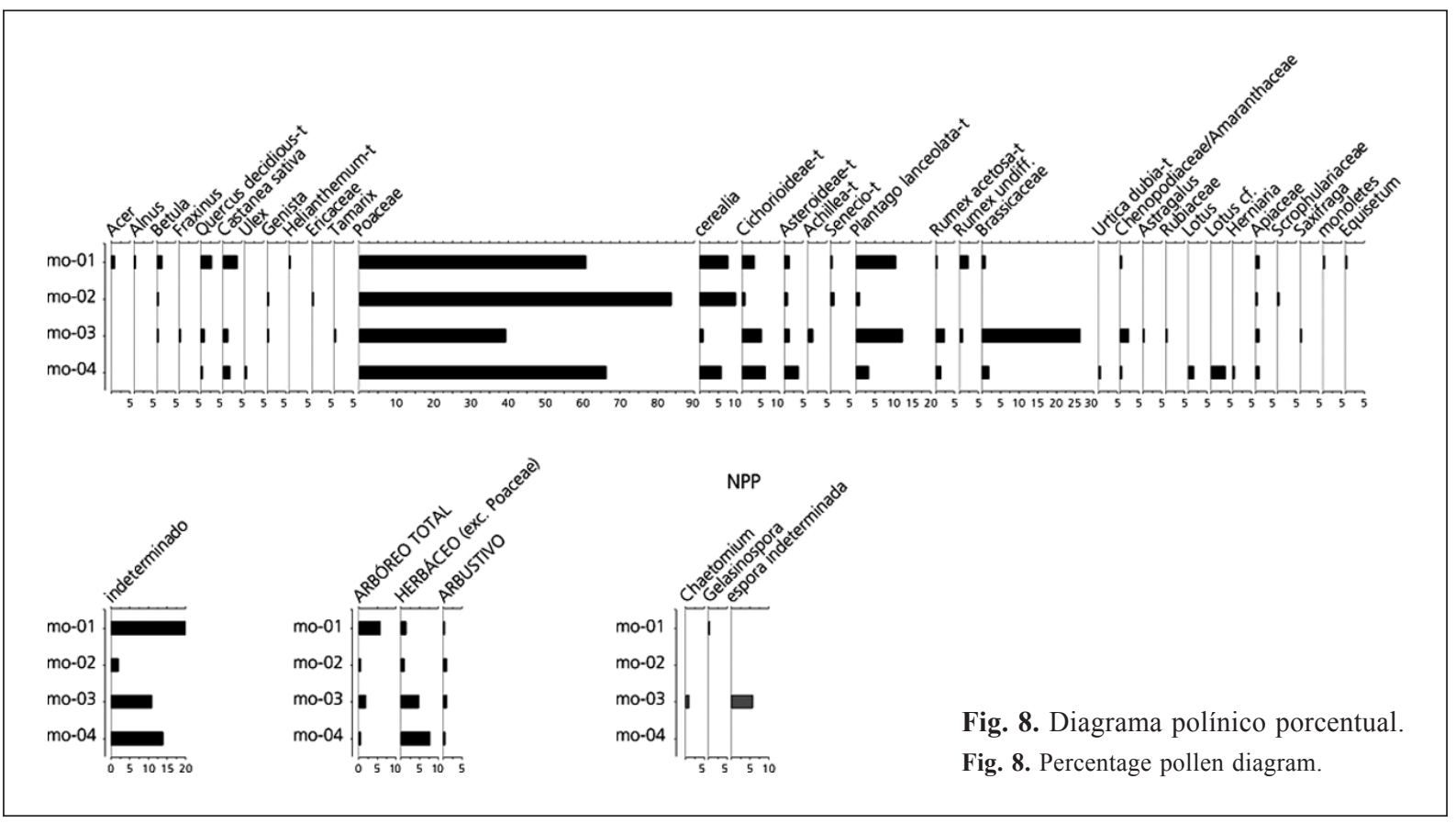

del sustrato, formado por cuarzo, feldespato, mica y caolinita. La presencia de pigmentación rojiza localizados en alguno de los silos tiene su origen en la formación de óxidos de hierro dentro de un proceso de lixiviación natural (SANJURJO 2010). No se han determinado otros elementos en el sedimento analizado, por lo que los datos no indican ningún tipo de preparación, argamasa o revestimiento de naturaleza mineral del corte.

\subsection{Polen}

- MO-01 (Fig. 9). Es la muestra que registra mayor contenido y variedad de polen arbóreo (Acer, Betula, Alnus, Quercus), destacando el abedul y el roble sobre el resto de taxones árboreos. Los porcentajes polínicos están dominados, pese a todo, por Poaceae, alcanzando aproximadamente un $60 \%$ de representación. Son también significativos los valores de polen de cereal $(7,7 \%)$ y castaño $(3,8 \%)$. Esta muestra registra también valores altos de Plantago lanceolata-t, con un 10\% de representación, así como la presencia de otros géneros, también ruderales, como Rumex o los tipos polínicos Cichorioideae-t y Ateroideae-t.

- MO-02 (Fig. 10). El registro polínico de la muestra 02 se caracteriza por un predominio del polen de Poaceae, superando el $80 \%$ de representación. La variedad de taxones es la

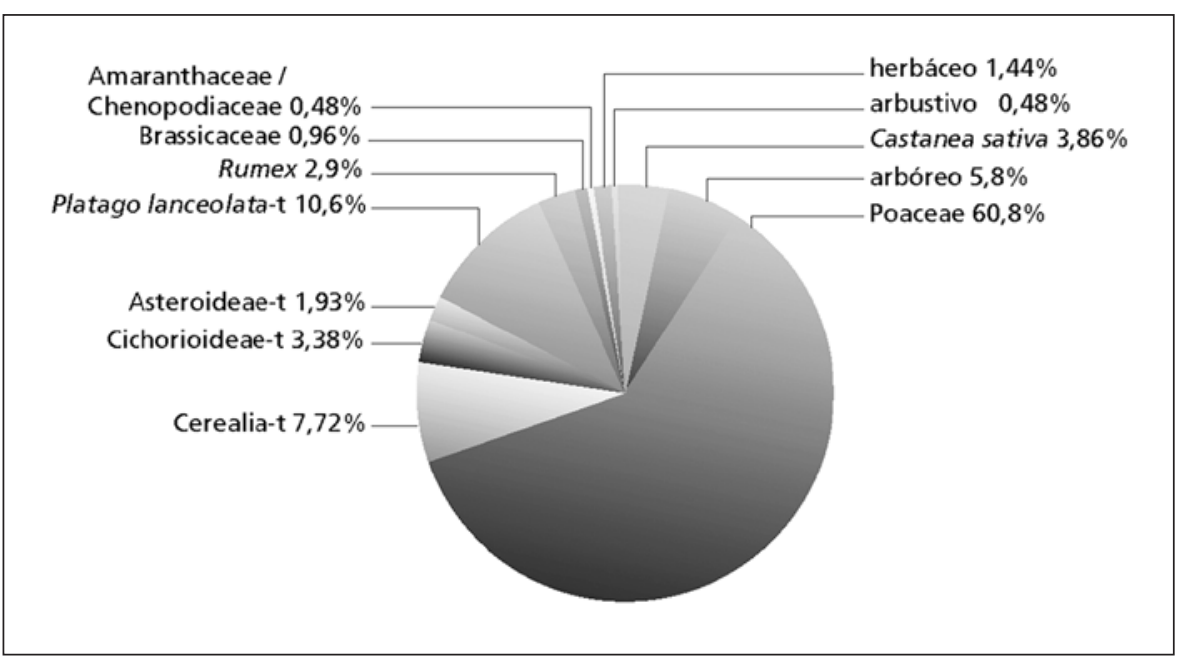

Fig. 9. Gráfico de valores porcentuales de polen de la muestra MO-01.

Fig. 9. Pie-chart showing the percentage pollen values of sample MO-01. 


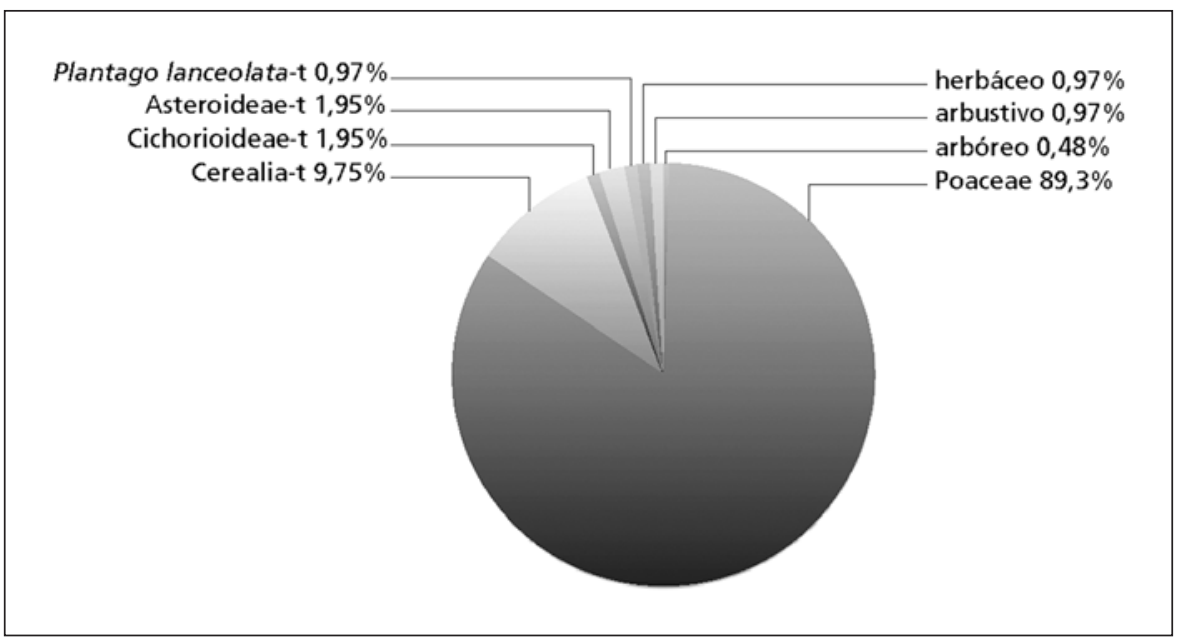

Fig. 10. Gráfico de valores porcentuales de polen de la muestra MO-02.

Fig. 10. Pie-chart showing percentage pollen values of sample MO-02.

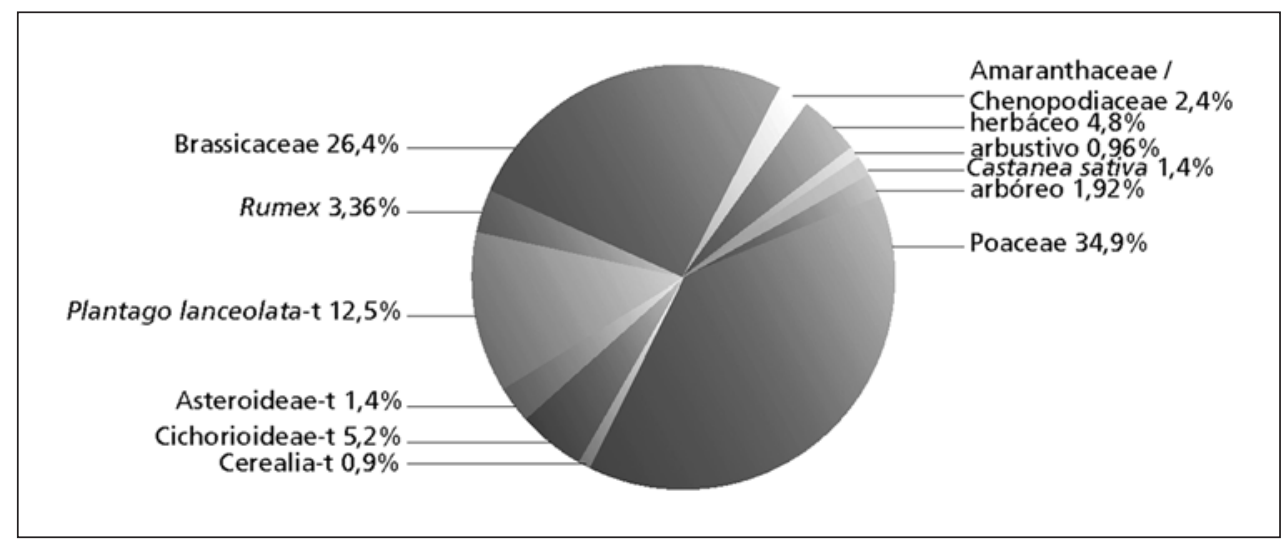

Fig. 11. Gráfico de valores porcentuales de polen de la muestra MO-03.

Fig. 11. Pie-chart showing percentage pollen values of sample MO-03.

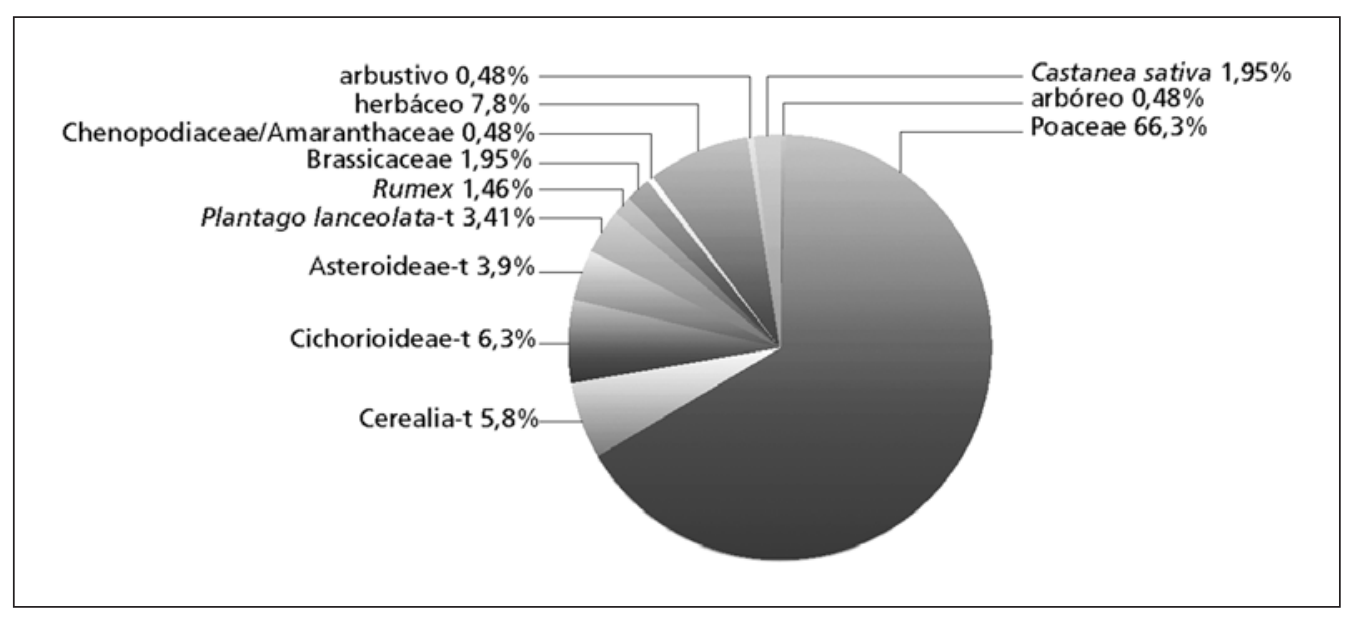

Fig. 12. Gráfico de valores porcentuales de polen de la muestra MO-04.

Fig. 12. Pie-chart showing percentage pollen values of sample MO-04. 
menor de las cuatro muestras analizadas, documentándose tan sólo 12 tipos polínicos. El espectro polínico registrado evidencia un porcentaje muy significativo de polen de cereal, que alcanza casi un $10 \%$ sobre el total de la muestra. Por el contrario, la proporción de taxones arbóreos, ruderales y otros tipos de herbáceas es la menor documentada. La flora arbustiva aparece evidenciada por la presencia de de Genista-t. y de Ericaceae.

- MO-03 (Fig. 11). La muestra 03 registró la variedad de taxones más elevada, con 21 tipos polínicos. A este dato se añade una distribución porcentual de los tipos polínicos ligeramente diferente al de las muestras 01, 02, y 04, lo cual es fundamentalmente debido al protagonismo de Brassicaceae, familia que consigue una representación superior al 25\%. El valor de Poaceae es menor, situándose esta vez en $39 \%$. Las especies arbóreas están representadas por Betula, Fraxinus, y Quercus, con valores inferiores a los observados en la muestra 01 . Los taxones ruderales están representados sobre todo en los elevados porcentajes de Plantago lanceolata-t (12\%), Rumex (3\%), Asteraceae $(8 \%)$ y Chenopodiaceae/Amaranthaceae $(2 \%)$. El registro de otras herbáceas es porcentualmente mayor que en las muestras 01 y 02 . Los valores de cereal registran valores inferiores (1\%) al del resto de muestras.

- MO-04 (Fig. 12). Esta muestra es la que registra menor porcentaje de polen arbóreo, con tan sólo evidencias aisladas de Quercus. Los valores de Poaceae llegan a alcanzar un $60 \%$ sobre el total. Entre la flora ruderal destacan las asteráceas $(10 \%)$, Brassicaceae $(1,9 \%)$, Plantago lanceolata-t (3\%) y Rumex (1,4\%). Los valores de polen de cereal se sitúan en 5,8\%, mientras que Castanea alcanza 1,95\%. El resto de los taxones herbáceos $(7,8 \%)$ ofrece valores superiores a los registrados en el resto de las muestras, situación que puede estar relacionada en este caso con las elevadas frecuencias de polen de Lotus.

\subsection{Fitolitos}

Los principales resultados obtenidos en el estudio de fitolitos se muestran en la Fig. 13. Una de las características comunes de las muestras analizadas es el elevado porcentaje de fracción insoluble al ataque del ácido - AIF (entre 77 y 91\%, aproximadamente, Fig. 13). Estos resultados indican que la composición mineralógica de las muestras es principalmente silícea; mientras que carbonatos, fosfatos y materia orgánica están presentes en una proporción relativamente menor. Este mayor predominio de elementos silíceos se da independiente de su localización, ya que los sedimentos de las dos estructuras analizadas presentan una proporción similar.

La estimación de fitolitos por gramo de FIA es significativamente elevada en la mayoría de las muestras (Fig. 13). Los sedimentos procedentes de la estructura UE76 son los que han proporcionado una mayor concentración (MO-01, 02 y 03, entre 1,7 y 2,6 millones de fitolitos por gramo de FIA). Sin embargo, la muestra de la UE129 ha librado cantidades significativamente menores (MO-04, 275.000 fitolitos/g de FIA). Los fitolitos se encontraban en buen estado de conservación con un bajo índice de disolución química en sus superficies (inferior al 10\%).

Los resultados del estudio morfológico revelan un predominio de fitolitos de la familia de las gramíneas, superior al $80 \%$ del total de fitolitos cuantificados (Fig. 14). Destaca la elevada proporción de morfotipos de las inflorescencias, parte de estas plantas donde se encuentran las semillas, especialmente en las muestras de la UE76 con valores entre el 47 y el $57 \%$ del total de fitolitos de gramíneas (Fig. 15). La mayoría de las morfologías identificadas pertenecen a gramíneas de tipo $\mathrm{C}_{3}$ (TWISS 1992), que se adscriben a la subfamilia pooideae (Fig. 16a). Las inflorescencias se encuentran representadas por la abundante presencia de las denominadas células largas dendríticas y las de margen equinado (Figs. 16b-c). Dentro de los fitolitos formados en otras partes de estas mismas plantas, se encuentran morfologías características de las hojas como los tricomas (Fig. 16d) y las células buliformes. Cabe destacar la abundancia significativa

\begin{tabular}{|c|c|c|c|c|c|}
\hline Muestra & Estructura & \% FIA & $\begin{array}{c}\text { Núm. fitolitos } \\
\text { 1 g de FIA }\end{array}$ & $\begin{array}{c}\text { Núm. fitolitos } \\
\text { identificados }\end{array}$ & $\begin{array}{c}\text { \% fitolitos } \\
\text { alterados }\end{array}$ \\
\hline MO-01 & UE76 & 79,2 & 1.725 .000 & 267 & 4,9 \\
\hline MO-02 & UE76 & 87,3 & 2.438 .000 & 445 & 8,1 \\
\hline MO-03 & UE76 & 77,6 & 2.590 .000 & 725 & 9,7 \\
\hline MO-04 & UE129 & 91,6 & 275.000 & 231 & 3 \\
\hline
\end{tabular}

Fig. 13. Localización de las muestras analizadas y principales resultados obtenidos en el estudio de fitolitos.

Fig. 13. Archaeological context of analysed samples and main results of phytollits analysis. 

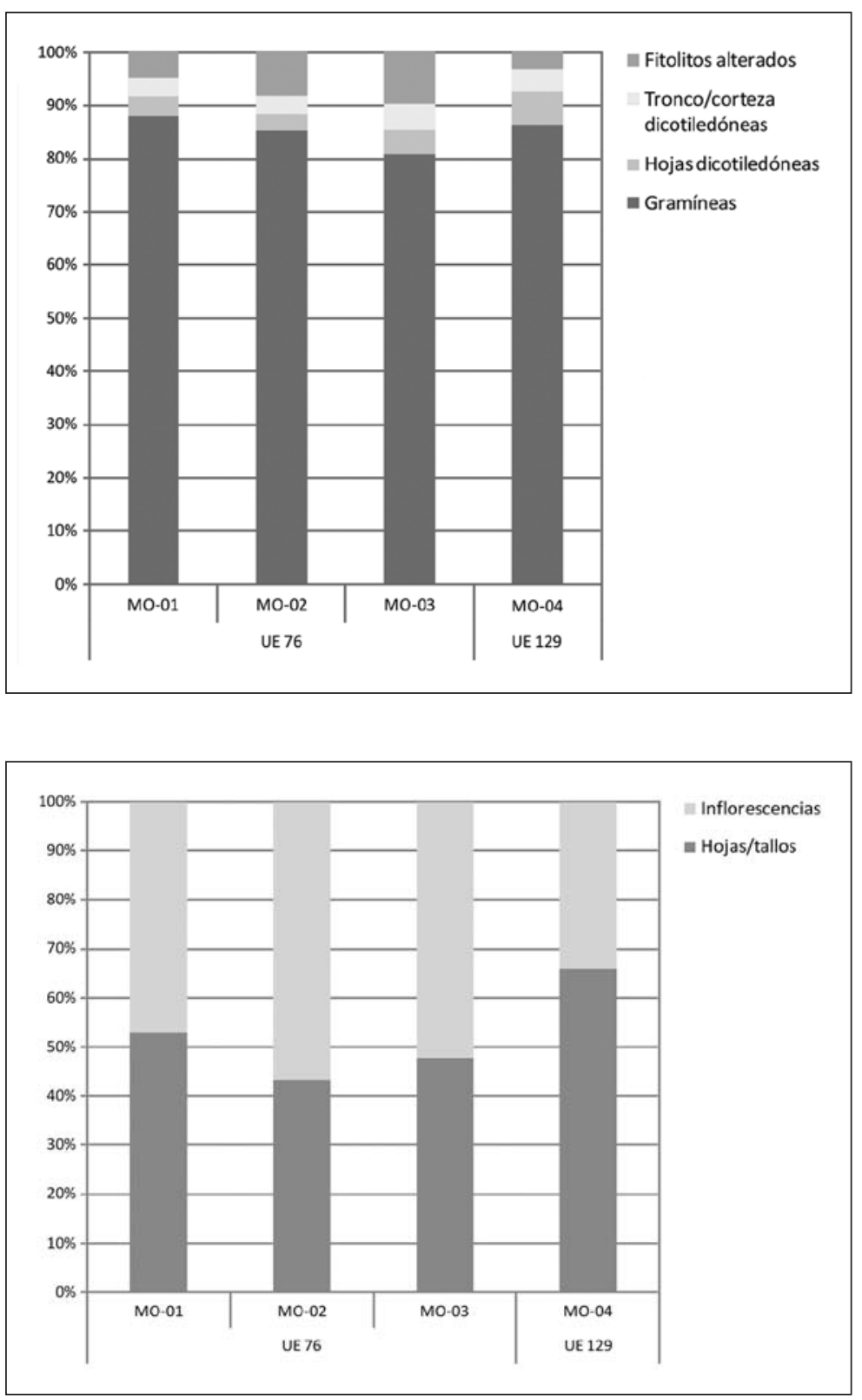

Fig. 14. Resultados porcentuales de los fitolitos identificados en las muestras.

Fig. 14. Results of the morphological analysis of the phytholiths identified in the samples.

Fig. 15. Resultados del análisis morfológico de fitolitos de gramíneas.

Fig. 15. Results of the morphological analysis of the Poaceae phytoliths. de estructuras multicelulares (esqueletos de silíceo), en todas las muestras de la UE76 (alrededor del 20\% del total de los fitolitos de gramíneas), mientras que éstas constituyen apenas el 1\% en la muestra M0-04 de la UE129. Las morfologías identificadas, formadas por células dendríticas en conexión anatómica, corresponden principalmente a las inflorescencias de trigo (Triticum sp.) (Fig. 16e).

Cabe mencionar también la presencia de diatomeas - organismos silíceos unicelulares, en todos los sedimentos analizados. Estos microrrestos biosilíceos, que parecen pertenecer a un tipo morfológico similar (Fig. 16f), se observan en abundancia en la muestra procedente del fondo de la estructura circular (UE76, MO-02).

\section{DISCUSIÓN}

En función de los resultados, la interpretación más plausible de la UE76 es la de un silo de almacenaje de cereal, con una alta probabilidad de que se trate de trigo (Fig. 17). La concentración de polen de cereal y poáceas es significativamente mayor en las muestras de la estructura en contacto con la pared (MO-01 y MO-02) - consecuentemente las que se relacionan con mayor probabilidad con su uso -, que en la del primer relleno del corte (MO-03), donde la representación de Cerealia y Poaceae es menor y existe un aumento importante de Brassicaceae. Las altas concentraciones de cereal, cuya dispersión polínica es particularmente baja (BоттемA 1992), 

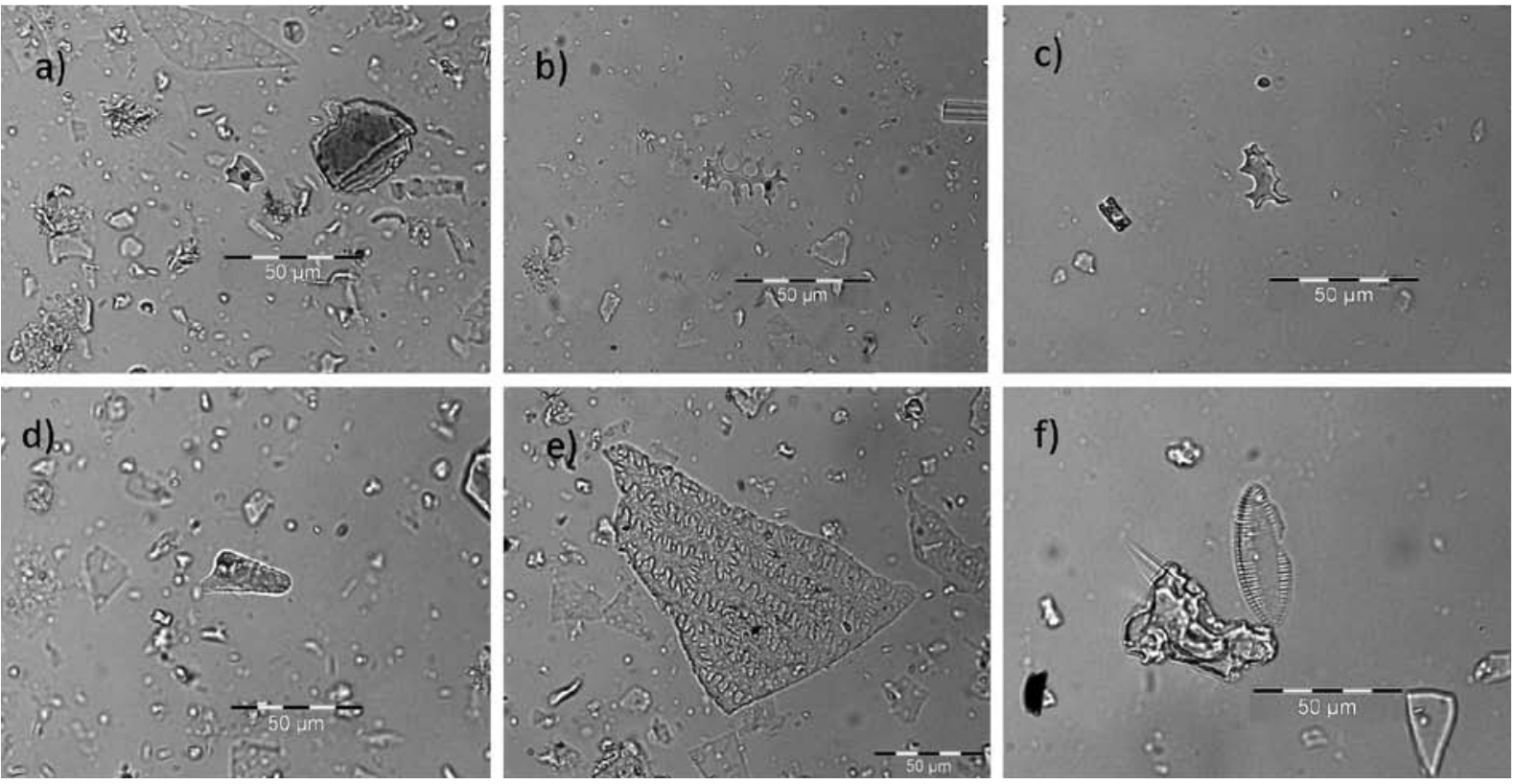

Fig. 16. Microfotografías de fitolitos y otros microrrestos identificados en las muestras $(400 \times)$. a) célula corta, b) célula larga dendrítica, c) célula larga equinada, d) tricoma, e) estructura multicelular dendrítica (Triticum sp.), f) diatomea.

Fig. 16. Photomicrographs of phytholiths and other microremains identified in the samples (400×). a) short cell rondel, b) dendritic long cell, c) echinate long cell, d) prickle, e) multicellular structure with dendritic cells, f) diatom.

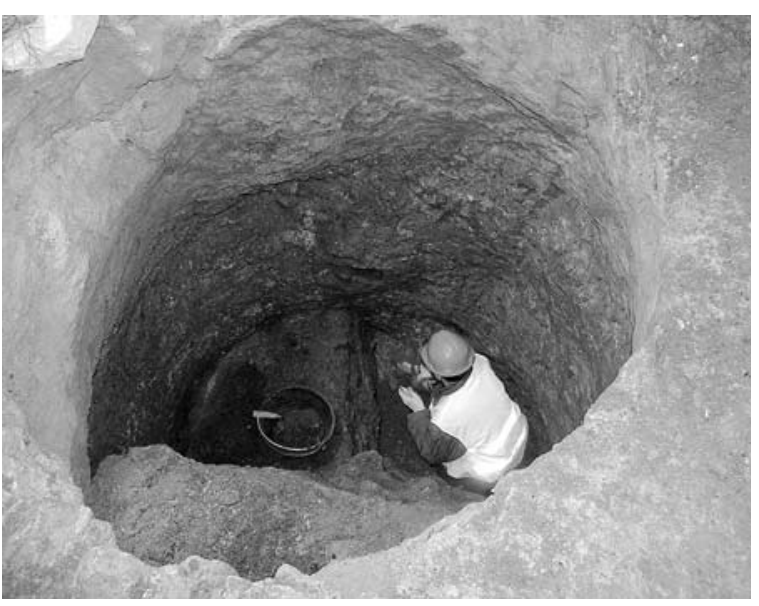

Fig. 17. Excavación del relleno de la UE76.

Fig. 17. Excavation of the fill of UE76.

posiblemente puedan ser explicadas por contacto directo del grano contenido dentro de la fosa. Los datos coinciden con los del análisis de fitolitos, donde los restos de Poaceae son el componente mayoritario, más del $80 \%$, de los cuales entre el $47 \%$ y el $57 \%$ provienen de las inflorescencias que alojan las semillas. Asimismo, las estructuras multicelulares caracterizadas por células dendríticas de poáceas en conexión anatómica corresponden a inflorescencias de trigo (Triticum sp.), lo que determina la especie contenida en el silo. La concentración de fitolitos de la inflorescencia indica también que el cereal fue depositado posiblemente sin limpiar. Cabe destacar la relevancia de los resultados obtenidos en el marco de este trabajo, dado que existen pocos estudios que hayan permitido interpretar arqueológicamente en términos de técnicas de almacenamiento este tipo de estructuras de las que suelen conservarse evidencias de sus usos secundarios como basureros una vez perdida su función original.

Una hipótesis alternativa que permitiese explicar el origen de estos vegetales en el interior de la estructura consistiría en su inclusión indirecta a través de excrementos animales. No obstante, la ausencia tanto de esporas de hongos de ecología coprófila (VAN GEEL \& APTROOT 2006) como de esferolitos fecales generados en el tracto intestinal (BROCHIER et al. 1992; CANTI 1997, 1998, 1999) no permite corroborar dicha propuesta.

En el interior se han encontrado esporas de especies vegetales pteridófitas, así como también diatomeas, que sugieren un ambiente húmedo. Estas condiciones poco adecuadas para el almacenaje de cereal, son posiblemente ajenas a la funcionalidad primaria de la estructura, y se corresponderían con su proceso de abandono o amortización posterior.

En cuanto a la UE129 existen grandes similitudes a la composición del espectro polínico procedente de la estructura UE76, compartiendo una representación mayoritaria de poáceas y niveles semejantes de $\mathrm{Ce}$ realia, diferenciándose esencialmente en el aumento de herbáceas, principalmente de Lotus sp. Existen 
ciertas dificultades para poder interpretar funcionalmente la formación de este estrato dentro de las actividades de almacenaje. Es posible que se trate de un acondicionamiento en la superficie del nivel de uso, y no de una estructura en sí misma. El análisis de fitolitos de la MO-04 coincide con MO-01, 02 y 03 pero con ciertas variaciones. Las concentraciones de restos son entre 7 y 10 veces menores por muestra, y el porcentaje de estructuras multicelulares dentro del total de gramíneas también es significativamente inferior, el $1 \%$ respecto al $20 \%$ de la UE76. Otras diferencias son la tipológica y la estratigráfica, pues se trata de una interfacies que se corta con la boca de una de las estructuras que interpretamos como silos, la UE115 (vid. Fig. 2). Una hipótesis factible que explicase la composición de esta muestra estaría en relación a una contaminación del sedimento por trabajos desarrollados en el entorno, ya que cronológicamente pudiesen ser coetáneos.

La técnica constructiva de las fosas apunta a una excavación directa, y puede que a una regularización de los cortes con las mismas herramientas. Los datos de los análisis químicos y sedimentológicos no han evidenciado restos de otros sedimentos, pigmentos o elementos como aglutinantes o enlucidos que significasen la existencia de un revestimiento de las paredes de la fosa UE76. Estos datos se complementan con la inexistencia de unidades estratigráficas que sugiriesen esta posibilidad, no documentadas durante la excavación arqueológica. Tampoco se han conservado restos macroscópicos de elementos orgánicos relacionados con el almacenaje.

Para su mejor conservación los silos suelen tener algún tipo de revestimiento mineral u orgánico, la inclusión de arenas o la filtración de humedades suelen ser motivos por los que los granos de cereal no tienden a estar en contacto directo con la pared del corte. Una hipótesis explicativa de esta ausencia, además de que no haya existido, es que no se hayan conservado macrorrestos vegetales. Por otra parte, cabe recordar que los resultados obtenidos en el estudio de fitolitos, indica que el componente vegetal está representado no sólo por inflorescencias de plantas gramíneas, parte donde se alojan sus semillas, sino también por fitolitos formados en tallos y hojas de este mismo grupo de plantas. Este dato indicaría que quizás el aislamiento de la pared estuviese hecho con paja, una práctica habitual de la que existen abundantes referencias tanto a nivel etnográfico, experimental y arqueológico (GAST \& Sigaut 1979; PANAGIOTAKOPULU et al. 1995; MADELLA 2001) como en las fuentes clásicas (SALIDO 2003-04). La conservación del grano en silos se encuentra en Plinio el Viejo (NH, XVIII 73, 306-307) y en Varrón (RR I, CVII2). Plinio indica que el grano normalmente no se estro- pea si se conserva en su espiga, pero como mejor se preserva es depositándolo en silos con paredes recubiertas de una capa de paja. Según Varrón, el trigo almacenado de esta manera en silos puede durar cincuenta años, y en el caso del mijo hasta cien. La presencia de polen de poáceas no cultivadas podría su uso con este fin (HEURGON 1978).

Aunque posiblemente existan más estructuras de almacenaje excavadas en Galicia en época medieval, éstas no han sido descritas en la bibliografía, en donde apenas encontramos referencias. Las más próximas, por paralelismos tipológicos, cronológicos y geográficos, son las de la Rúa Bordel (Padrón, A Coruña) (RÚA 2008, 2009), lugar en el que se ha excavado una agrupación de silos y fosas amortizados como basureros, por lo que contienen gran cantidad de restos correspondientes a su abandono y no necesariamente asociados a su funcionalidad original, entre ellos una acumulación de semillas de cerezas (Prunus avium). En el interior de una de los silos se conservó el recebo interior de arcilla (RÚA 2009) y un fragmento de la tapadera que lo cerraba elaborada en madera de castaño (Castanea sativa) (MARTín 2010) (Fig. 18). Las estructuras de este yacimiento se han interpretado como un área de almacenaje extramuros del burgo medieval de Padrón en el tránsito de la Alta a la Baja Edad media (RÚA 2009), cercana a la sede del primitivo obispado de Iria Flavia.

También hay referencias a fosas circulares, aunque de menor tamaño y posiblemente difieran en funcionalidad, en la ocupación de los siglos VI-VII AD de A Pousada (Santiago de Compostela) (BALLESTEROS et al. 2006), y en el VII-VIII AD en Carballeira do Espíritu Santo (Silleda, Pontevedra) (BAllesteros \& Blanco 2010). Las dimensiones de las fosas en A Pousada (Fig. 19), correspondientes a un establecimiento rural, son sensiblemente de menor capacidad, oscilan entre 0,80 a 2 metros de diámetro y no alcanzan el metro de profundidad (BALlesteros et al. 2006).

Por lo común, el tipo de silos de la intervención de los Almacenes El Pilar, de boca ancha y sección cilíndrica, se asocian a un abastecimiento relativamente frecuente del producto contenido, en contraposición con aquellos de boca más pequeña y fondo ensanchado utilizados para el almacenaje a largo plazo (PujANTE 2006). Dada su capacidad suelen formar parte de un almacenaje comunitario, sirviendo de banco de recursos y reserva de alimentos en épocas de escasez, como también para el intercambio comercial o incluso la reposición de cosechas. Sin embargo tiende a existir algún tipo de stock y acciones especulativas sobre su consumo, y a estar controlados por algún organismo público o privado (Ros \& RUAS 2010). 

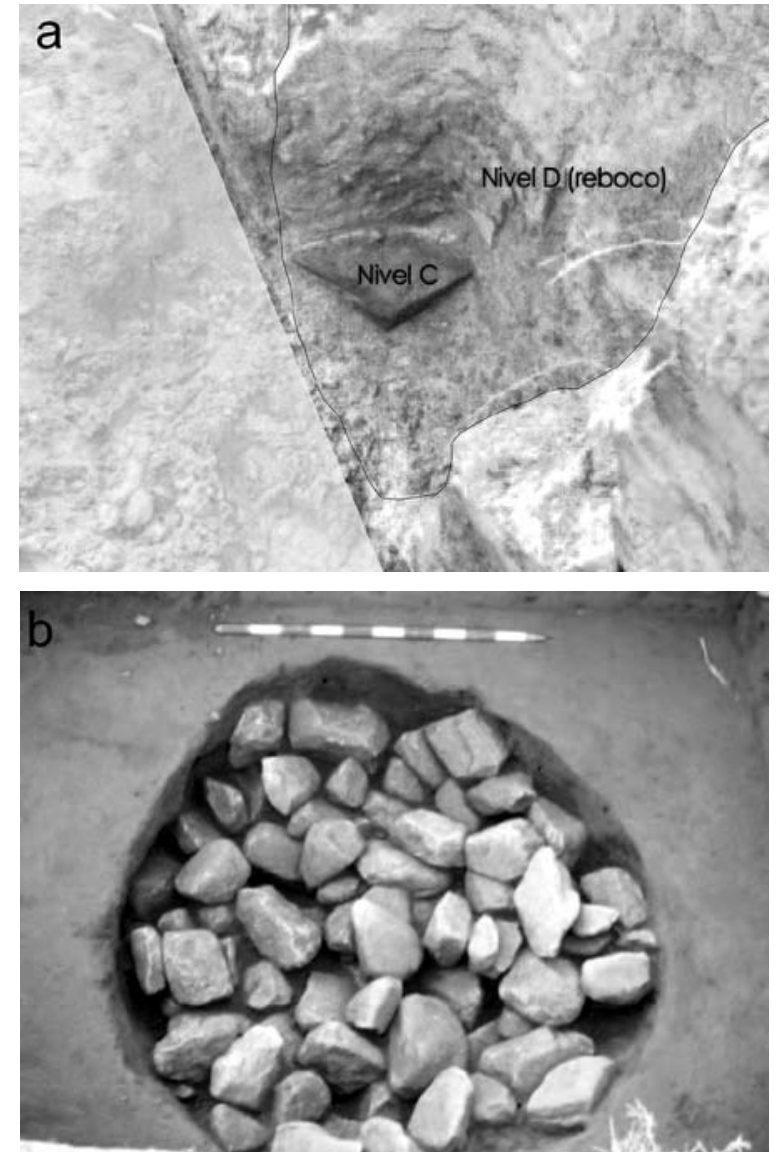

Fig. 18. Silos de la Rúa Bordel: a) sección - se observa un fragmento de tapadera de castaño (modificado a partir de V. Rúa 2009); b) colmatación de piedras (RÚA 2008) de otro de los silos.

Fig. 18. Storage pits from Rúa Bordel (Padrón, A Coruña). a) section of a storage pit showing lid fragment made from chestnut (modified from V. Rúa 2009); b) accumulation of stones (RÚA 2008) in another storage pit.

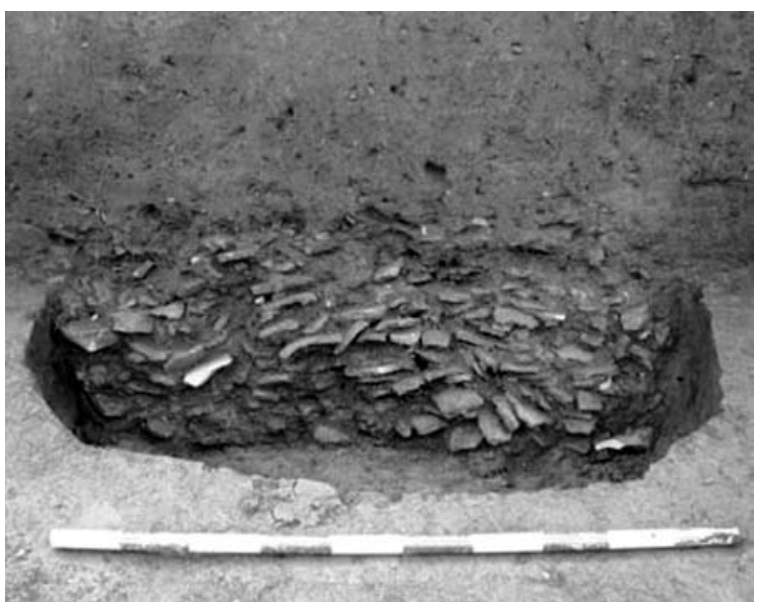

Fig. 19. Fosa del yacimiento de A Pousada (Santiago de Compostela, A Coruña) (PARCERo \& AYÁN 2009).

Fig. 19. Pit from the site of A Pousada (Santiago de Compostela, A Coruña) (PARCERO \& AYÁN 2009).
Debemos tener en cuenta que los restos recuperados se enmarcan en una época crucial en el desarrollo de la ciudad. Durante el final de la Alta Edad Media, Compostela viviría el nacimiento de su consagración como centro de peregrinación. Entre los años 813-830, Teodomiro, obispo de Iria Flavia, había promulgado la aparición de la tumba del apóstol Santiago. Este hecho contó con el apoyo de Alfonso II que mediante la llamada "dote del rey Casto" otorgaba a la comunidad monástica existente un locus en torno al sepulcro (López ALSINA 1988). La monarquía asturiana había encontrado de este modo una importante herramienta de afirmación ideológica del cristianismo frente al dominio musulmán de la Península, y su colaboración fue constante en esta primera época (LÓPEZ ALSINA 1988). Un ejemplo es la consagración de la iglesia de Santiago en el 899 por Alfonso III de Asturias.

El área original en torno al Locus Sancti Iacobi comenzó siendo un núcleo eminentemente rural (LÓPEZ ALSINA 1988) sobre un espacio en el que existió un poblamiento anterior. Las excavaciones arqueológicas han determinado restos desde época romana en el área de la Praza da Quintana y bajo la actual Catedral (SUÁrEZ \& CAAMAÑo 2003). Desde el siglo IX hasta mediados del siglo XI, el desarrollo del área compostelana desembocó en la formación de una villa. El locus original se protegió con un cierre amurallado de $3 \mathrm{Ha}$ de extensión en el período 960-968, mandado construir por Sisnando II (Fig. 20). Fuera de este recinto existían varias áreas habitadas, correspondientes a pequeños vici, como el denominado vicus francorum, en la actual Rúa do Franco (ARMAS 2003). También en la zona del castro, próxima a la iglesia de San Fiz de Solovio, entre las actuales Rúa do Preguntoiro y la Rúa do Castro, ya ocupada antes del hallazgo del sepulcro (LÓPEZ Alsina 1988; ARMAS 2003). Para proteger esta área en crecimiento se construyó una empalizada que sería destruida por una razia de Almanzor (997). Aunque quizás esta empalizada fuese el germen del perímetro de la ciudad bajomedieval no es hasta Cresconio II (1037-1066) cuando se edifica la muralla de piedra que delimitaría la villa burguensis de $30 \mathrm{Ha}$ de extensión que aglutinará tanto a estos núcleos como a áreas ocupadas por huertos (LÓPEZ ALSINA 1988). En el interior se construiría la catedral románica, iniciada hacia el 1075 y consagrada en el 1211 por Alfonso IX de León.

En el marco de esta evolución urbana, la intervención arqueológica se emplazaría en un espacio muy próximo a donde estuvo la muralla del locus, quizás contigua a una de las torres y a uno de los accesos del este según la interpretación de López Alsina (1988). El área de almacenaje guarda además 


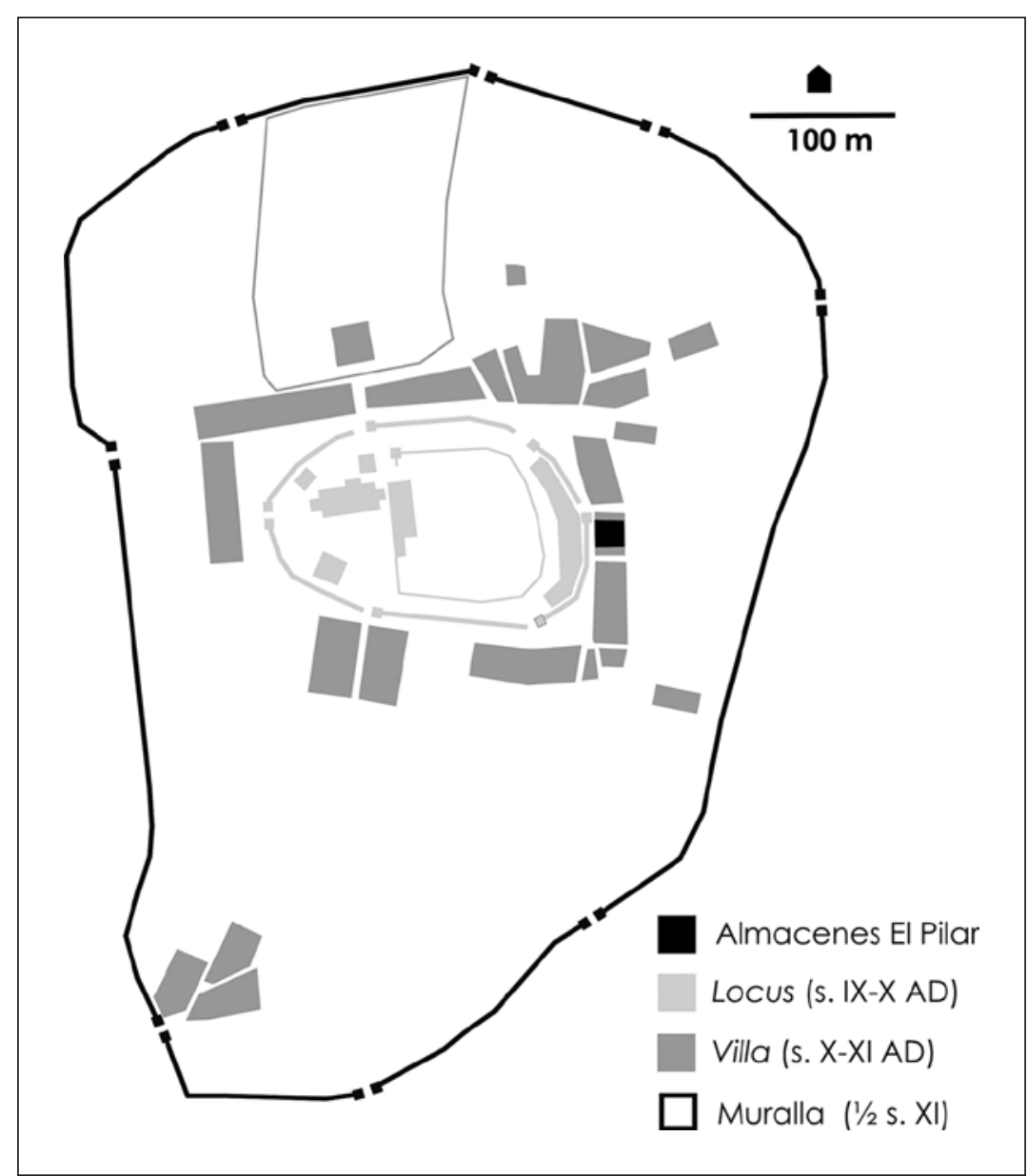

Fig. 20. El área de intervención dentro de la evolución del Locus Sancti Iacobi (s. IX) a la muralla de Cresconio (1037-1066) (reelaborado a partir de F. López Alsina 1988).

Fig. 20. Excavation area shown within the evolution of the Locus Sancti Iacobi (9th century) to the wall of the Cresconio (1037-1066) (reworked from F. López Alsina 1988).

otra interesante localización, se encuentra en plena Rúa do Preguntoiro. El origen del nombre de esta calle - Preconitorium - es el de la lectura pública del pregón (ARMAS 2003) en espacios públicos como plazas, posiblemente utilizadas además para el intercambio de mercancías. En el siglo XII el mercado o foro se emplazaba 70 metros al norte de la excavación, en lo que posteriormente se llamaría la Praza do Campo (ARMAS 2003), la actual Praza de Cervantes.

Dada la concentración de estructuras y su tamaño, los silos de trigo no estarían orientados a un consumo doméstico, dependiente de una unidad familiar. Este tipo de almacenaje sugiere una propiedad comunitaria y por lo tanto, posiblemente una gestión y un acceso regulados. Sin embargo poco, o más bien nada, podemos afirmar en este texto sobre la propiedad del espacio, sólo aventurar hipótesis. Una de las interpretaciones es que haya pertenecido a alguna propiedad nobiliaria, muy probablemente eclesiástica por el marcado carácter religioso de la villa. En la Edad Media el trigo fue el cereal más apreciado por los señores (PORTELA 1978). En documentos de los monasterios del obispado de Tui (Pontevedra) de los siglos XII y XIII, además del gran número de menciones a la vid, destacan los cereales, en una cantidad muy pareja trigo, cebada y mijo, y en menor número centeno (PorTela 1978). Más allá del número de apariciones en la documentación, los contratos de foro señalan que la proporción de trigo empleado en el pago de rentas es menor que la de los demás cereales (PORTELA 1978), lo que nos indica que si la cantidad necesaria para satisfacer el mismo pago es inferior en trigo su valor de cambio sería mayor que la cebada, el mijo y el centeno. En este sentido hemos de enumerar las varias comunidades establecidas ya en origen del locus: Antealtares (la más próxima), Corticela y Solovio, y otras que se irían estableciendo, como la propia a Santiago o la de San Martiño Pinario. La nobleza necesitaría disponer de un lugar donde se acumulasen las rentas percibidas por sus propiedades. Otra hipótesis es la de un espacio relacionado - por proximidad - con el mercado del foro, donde se almacenasen los productos con los que se comerciaba. Tampoco hay que olvidarse de una tercera posibilidad como es la existencia de una alhóndiga o pósito para la venta de cereales en épocas de escasez. 


\section{CONCLUSIÓN}

La interpretación más plausible de las fosas de planta circular y mayor profundidad en función de los análisis realizados es la de silos de almacenaje. En ellos se habría llevado a cabo una acumulación de trigo (Triticum sp.) en un momento de expansión del burgo medieval compostelano. La excavación de fosas en el substrato es un método atestiguado desde la Prehistoria para el almacenamiento de cereales. Basado en principios anaeróbicos, origina una atmósfera cerrada con falta de oxígeno y saturación de $\mathrm{CO}_{2}$ que impide la germinación de los granos - estos pueden permanecer en estado latente durante años -, y evita la proliferación de insectos y hongos.

Las dataciones indican que el proceso de colmatación de los silos, una vez perdido su uso para el almacenaje se inicia a grandes rasgos entorno a los siglos XI/XII en la UE76 y la UE115. En el caso de la UE129, aunque no sea posible definirla funcionalmente dentro del conjunto, podría estar datando un episodio en el cual los silos estuvieron en uso.

\section{Agradecimientos}

A María Martín Seijo, a Joeri Kaal y a Ana M. Varela Montes.

La extracción química de los fitolitos fue realizada en el Laboratorio del Departamento de Prehistoria, Historia Antigua y Arqueología de la Universidad de Barcelona por Francisco Hernández Camacho, del Grupo de Estudios Paleoecológicos y Geoarqueológicos (GEPEG).

\section{BIBLIOGRAFÍA}

ALBERT, R.M. 2000. Study of ash layers through phytolith analyses from Middle Paleolithic levels of Kebara and Tabun Cave, Mt. Carmel (Israel). Universidad de Barcelona. Tesis Doctoral inédita.

AlberT, R.M. \& WeINER, S. 2001. Study of phytoliths in prehistoric ash layers using a quantitative approach. In J.D. Meunier \& F. Colin (eds.) Phytoliths, Applications in Earth Sciences and Human History. Lisse: A.A. Balkema Publishers: 251-266.

Albert, R.M.; Tsatskin, A.; Ronen, A.; LAVi, O.; Estroff, L.; LeV-YAdun, S. \& WeINER, S. 1999. Mode of occupation of Tabun Cave, Mt. Carmel, Israel during the Mousterian Period: A study of the sediments and phytoliths. Journal of Archaeological Science 26: 1249-1260.

AlCAlDE, G. \& BuXó, R. 1991. Experimentació d'emmagatzematge i explotació de Triticum dicoccum Sch, a la Vall del Llierca (La Garrotxa). Cypsela 9: 87-94.

ARmas CAStro, J. 2003. O afianzamento da realidade urbana despois do ano mil. In E. Portela Silva (coord.) Historia da Cidade de Santiago de Compostela. Santiago de Compostela:
Consorcio da Cidade de Santiago de Compostela, Universidade de Santiago de Compostela: 79-122.

Ballesteros Arias, P. \& Blanco-rotea, R. 2010. Aldeas y espacios agrarios altomedievales en Galicia. In J.A. Quirós Castillo, The Archaeology of Early Medieval Villages in Europe. Documentos de Arqueología e Historia, 1. Universidad del País Vasco: 115-135.

Ballesteros Arias, P.; Blanco-Rotea, R. \& Prieto Martínez, P. 2006. The Early Mediaeval site of A Pousada (Santiago de Compostela, A Coruña, Spain). Apéndice en J.A. Quirós Casti1lo \& A. Vigil-Escalera Guirado. Networks of peasant villages between Toledo and Velegia Alabense, Northwestern Spain (V-X ${ }^{\text {th }}$ centuries). Archeologia Medievale 33: 115-128.

BEHRE, K.-E. 1981. The interpretation of anthropogenic indicators in pollen diagrams. Pollen et Spores 13: 225-45.

BEUG, H.-J. 2004. Leitfaden der Pollenbestimmung für Mitteleuropa und angrenzende Gebiete. München: Verlag Dr. Friedrich Pfeil.

Bottema, S. 1992. Prehistoric cereal gathering and farming in the Near East: the pollen evidence. Review of Palaeobotany and Palynology 73: 21-33.

Bradley, R.S.; Briffa, K.S.; Cole, J.; Hughes M.K. \& Osborn, T.J. 2003. The climate of the last millennium. In K. Alverson, R.S. Bradley \& T.F. Pedersen (eds.) Paleoclimate, Global Change and Future. Berlin: Springer Verlag: 105-141.

Brochier, J.E.; Villa, P.; Giacomarra, M. \& TAgliacozzo, A. 1992. Shepherds and sediments: geo-ethnoarchaeology of pastoral sites. Journal of Anthropological Archaeology 11: 47-102.

BRown, D.A. 1984. Prospects and limits of a phytolith key for grasses in the central United States. Journal of Archaeological Science 11: 345-368.

CANTI, M.G. 1997. An investigation of microscopic calcareous spherulites from herbivore dungs. Journal of Archaeological Science 24: 219-231.

CANTI, M.G. 1998. The micromorphological identification of faecal spherulites from archaeological and modern materials. Journal of Archaeological Science 25: 435-444.

CANTI, M.G. 1999. The production and preservation of faecal spherulites: animals, environment and taphonomy. Journal of Archaeological Science 26: 251-258.

DesPrat, S.; SÁNChez GoÑI, M.F. \& LOUTRE, M.-F. 2003. Revealing climatic variability of the last three millennia in northwestern Iberia using pollen influx data. Earth and Planetary Science Letters 213: 63-78.

FÆGRI, K. \& IVERSEN, J. 1989. Textbook of Pollen Analysis, fourth ed. New Jersey: The Blackburn Press.

GAST, M. \& Sigaut, F. (dirs.) 1979. Les techniques de conservation des grains à long terme. Leur rôle dans la dynamique des systèmes de cultures et des sociétes. París: Éditions du Centre National de la Recherche Scientifique.

GonzÁlez Méndez, M. \& LuAces AnCA, J. 2009. A cerca da cidade: Santiago de Compostela. Santiago de Compostela: Oficina da Cidade Histórica e Rehabilitación, Concello de Santiago.

Heurgon, J. (ed.) 1978. Varron-Économie Rurale. Livre I. Paris: Les Belles Lettres.

Lebreiro, S.; FrancÉs, G.; ABrantes, F.F.G.; Diz, P.; BARTEls-JónsdótTir, H.B.; Stroynowski, Z.N.; Gil, I.M.; PenA, L.D.; Rodrigues, T.; Jones, P.D.; Nombela, M.A.; Alejo, I.; BRIFFA, K.R.; HARRIS, I. \& GRIMALT, J.O. 2006. Climate change and coastal hydrographic response along the Atlantic Iberian margin (Tagus Prodelta and Muros Ria) during the last two millennia. The Holocene 16: 1003. 
López Alsina, F. 1988. La ciudad de Santiago de Compostela en la Alta Edad Media. Santiago de Compostela: Ayuntamiento.

LÓPEZ DíAZ, M. 2003. Organización e actividade política. In E. Portela Silva (coord.) Historia da Cidade de Santiago de Compostela. Santiago de Compostela: Consorcio da Cidade de Santiago de Compostela, Universidade de Santiago de Compostela: $305-360$.

MADELlA, M. 2001. Understanding archaeological structures by means of phytolith analysis: a test from the Iron Age site of Kilise Tepe - Turkey. In J.D. Meunier \& F. Colin (eds.) Phytoliths, Applications in Earth Sciences and Human History. Lisse: A.A. Balkema Publishers: 173-182.

Madella, M.; Alexandre, A. \& BALl, T.B. 2005. International Code for phytolith Nomenclature 1.0. Annals of Botany 96: 253-260.

MARTín SeiJo, M. 2010. Análise xilolóxica das madeiras do xacemento de Bordel (Padrón, A Coruña). In M. Martín Seijo, A. Rico Rey, A. Teira Brión, I. Picón Platas, I. García González \& E. Abad Vidal (eds.) Guía de arqueobotánica. Santiago de Compostela: Xunta de Galicia. Informe anexo en CD.

Martínez Cortizas, A.; Pontevedra Pombal, X.; García Rodeja, E.; Novoa Muñoz, J.C. \& ShotyK, W. 1999. Mercury in a Spanish peat bog: archive of climate change and atmospheric metal deposition. Science 284: 939-942.

Martínez Cortizas, A.; Mighall, T.; Pontevedra Pombal, J.C.; Novoa Muñoz, E.; Peiteado Varela, E. \& PiñeIRO REBOLO, R. 2005. Linking changes in atmospheric dust deposition, vegetation change and human activities in northwest Spain during the last 5300 years. The Holocene 15 (5): 698-706.

Mulholland, S.C. \& RAPP, JR.G. 1992. A morphological clasification of grass silica-bodies. In Jr. G. Rapp \& S.C. Mulholland (eds.) Phytolith Systematics, Emerging Issues, Advances in Archaeological and Museum Science. New York: Plenum Press: 65-89.

MuÑoz Sobrino, C.; RAmil Rego, P. \& Rodríguez Guitián, M. 1997. Upland vegetation in the north-west Iberian peninsula after the last glaciation: forest history and deforestation dynamics. Vegetation History \& Archaeobotany 6: 215-233.

PArCero OubiñA, C. \& AyÁn Vila, X.M. 2009. Almacenamiento, unidades domésticas y comunidades en el noroeste prerromano. In R. García Huerta, D. Rodríguez González (coords.) Sistemas de almacenamiento entre los pueblos prerromanos peninsulares. Cuenca: Ediciones de la Universidad de Castilla La Mancha: 367-402.

PIPERNO, D.R. 2006. Phytoliths: A comprehensive guide for archaeologists and paleoecologists. Lanham: AltaMira Press.

Plinio El Viejo. 1960. Histoire Naturelle (citado NN). J. André (ed.). Paris: Les Belles Lettres.

Portela Silva, E. 1978. La región del Obispado de Tuy en los siglos XII a XV. Santiago de Compostela: Imprenta El Eco Franciscano.

Pujante Martínez, A. 2006. El yacimiento prehistórico de Los Molinos de Papel (Caravaca de la Cruz, Murcia). Intervención arqueológica vinculada a las obras de infraestructura del plan parcial SCR2, 1999-2000. Memorias de Arqueología 14 (1999): 133-172.
Ramil Rego, P.; GómeZ-ORellana, L.; MuÑOZ-SObrino, C.; García-Gil, S.; Iglesias, J.; PÉrez Martínez, M.; Martínez Carreña, M. \& De Novoa Fernández, B. 2009. Cambio climático y dinámica del paisaje en Galicia. Recursos Rurais 5: 21-47.

ReIlle, M. 1992. Pollen et spores d'Europe et d'Afrique du nord. Marseille: Laboratoire de Botanique historique et Palynologie, Université d'Aix-Marseille III.

Ros, J. \& RuAS, M.P. 2010. Production and Storage of Food Plants in Eastern Languedoc $10^{\text {th }}-11^{\text {th }}$ century A.D. Thes sites of Dassarques and lunel-viel (Hérault, France). $15^{\text {th }}$ Symposium of IWGP, Wilhelmshaven, 30 May-5 June 2010. Póster.

RosEN, A.M. 1992. Preliminary identification of silica skeletons from Near Eastern archaeological sites: an anatomical approach. In Jr. G. Rapp \& S.C. Mulholland (eds.) Phytolith Systematics, Emerging Issues, Advances in Archaeological and Museum Science. New York: Plenum Press: 129-148.

Rosende VAldÉs, A.A. 2004. Unha Historia urbana: Compostela, 1595-1780. Santiago de Compostela: Nigratrea; Concellalía do Casco Histórico e Rehabilitación.

RÚA CARRIL, V. 2008. Sondaxes manuais en proxecto básico para obras de construción dun edificio de vivendas (38) na rúa Bordel, Padrón. Actuacións arqueolóxicas. Informes 2006. Santiago de Compostela: Xunta de Galicia: 127-127.

RÚA CARRIL, V. 2009. Escavación en área para obras de construción dun edificio de vivendas na rúa Bordel, Padrón. Actuacións arqueolóxicas. Informes 2007. Santiago de Compostela: Xunta de Galicia: 127-128.

SALIDO DomíngueZ, J. 2003-04. La documentación literaria aplicada al Registro Arqueológico: Las técnicas de construcción de los graneros romanos rurales. Espacio, Tiempo y Forma, Prehistoria y Arqueología 16-17, Serie I: 463-478.

SANJURJO SÁNCHEZ, J. 2010. Datación por luminiscencia de materiales de sedimentos y una cerámica de un solar de la calle Preguntoiro s/n de Santiago de Compostela. Laboratorio de Datación por Luminicencia. Unidad de Geocronología. Universidade de A Coruña. Informe.

SuÁrez Otero, J. 2003. Do Locus Sancti Iacobi ó Burgo de Compostela. In E. Portela Silva (coord.) Historia da Cidade de Santiago de Compostela. Santiago de Compostela: Consorcio da Cidade de Santiago de Compostela, Universidade de Santiago de Compostela: 49-75.

SuÁrez Otero, J. \& CAAmaño Gesto, M. 2003. Santiago antes de Santiago. In E. Portela Silva (coord.) Historia da Cidade de Santiago de Compostela. Santiago de Compostela: Consorcio da Cidade de Santiago de Compostela, Universidade de Santiago de Compostela: 23-48.

Twiss, P.C. 1992. Predicted world distribution of $\mathrm{C}_{3}$ and $\mathrm{C}_{4}$ grass phytoliths. In Jr. G. Rapp \& S.C. Mulholland (eds.) Phytolith Systematics, Emerging Issues, Advances in Archaeological and Museum Science. New York: Plenum Press: 113-128.

TwISS, P.C.; SuEss, E. \& SMITH, R.M. 1969. Morphological classification of grass phytoliths. Soil Science Society of America Proceedings 33: 109-115.

VAn Geel, B. \& Aptroot, A. 2006. Fossil ascomycetes in Quaternary deposits. Nova Hedwigia 82: 313-329. 